\title{
Characterization of biodegradable films based on extracellular polymeric substances extracted from the thermophilic microalga Graesiella sp.
}

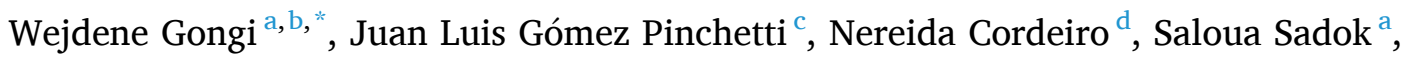 \\ Hatem Ben Ouada ${ }^{a}$ \\ ${ }^{a}$ Laboratory of Blue Biotechnology \& Aquatic Bioproducts, National Institute of Marine Sciences and Technologies, 5000 Monastir, Tunisia \\ ${ }^{\mathrm{b}}$ National Institute of Agronomy, University of Carthage, Tunis 1082, Tunisia \\ ${ }^{\mathrm{c}}$ BEA - Spanish Bank of Algae, Institute of Oceanography and Global Change (IOCAG), University of Las Palmas de Gran Canaria, Muelle de Taliarte s/n, 35214 Telde, \\ Canary Islands, Spain \\ d LB3-Faculty of Science and Engineering, University of Madeira, 9000-390 Funchal, Portugal
}

\section{A R T I C L E I N F O}

\section{Keywords:}

Graesiella sp.

EPS film

Physicochemical properties

Antioxidant

Meat shelf life

\begin{abstract}
A B S T R A T
In this research, a new type of biodegradable film based on the extracellular polymeric substances (EPS) and isolated from the thermophilic microalga Graesiella sp., was formulated and characterized. The EPS film was $0.221 \mathrm{~mm}$ thick. Atomic force microscopy and scanning electron microscopy images revealed a homogeneous character with a lamellar microstructure. The EPS film displayed yellowish color, high transparency, high ultraviolet barrier properties, and low oxygen $(0.008 \mathrm{SI})$, and water-vapor permeability $(0.037 \mathrm{SI})$. Film tensile strength (16.24 MPa) and elongation at break (4.76\%) were in the range of common biofilms and the thermal analyses showed high transition temperature $\left(126^{\circ} \mathrm{C}\right.$ ) and high thermal stability (up to $800{ }^{\circ} \mathrm{C}$ ). Compared to ascorbic acid, results indicated that the EPS film shows a higher antioxidant activity, mainly as $\beta$-carotene antibleaching (84\%), DPPH- free radical scavenging ability (80\%), and ferrous iron-chelating (55\%).

Graesiella sp., EPS film effects on beef meat packaging were studied during nine days of cold storage. Compared to polyvinylchloride-packed meat, EPS-packed meat samples showed higher stability of color (redness $=13.6)$ and $\mathrm{pH}(5.85)$ during storage and low proliferation of total viable counts $\left(4.04 \mathrm{CFU} \cdot \mathrm{g}^{-1}\right.$ ) and Pseudomonas bacteria (4.09 CFU.g ${ }^{-1}$ ). They also exhibit lower drip loss (9\%) and less metmyoglobin (32\%), heme iron $\left(4.87 \mu \mathrm{g} \cdot \mathrm{g}^{-1}\right.$ ) total volatile basic nitrogen (TVB-N $=22.96 \mathrm{mg} \cdot \mathrm{kg}^{-1}$ ), and lipid oxidation $\left(\mathrm{MDA}=0.025 \mathrm{mg} \cdot \mathrm{kg}^{-1}\right)$. The obtained results highlight the potential for use of microalgae EPS as a new filmforming material that could be applied in beef meat preservation.
\end{abstract}

\section{Introduction}

Recently, plastics have become a source of worrying contamination due to their abundance, their persistence in nature, as well as their harmful effects on biodiversity and the environment [1]. Plastics are mainly used as packaging materials, up to $38 \%$, and most are released into the environment after a single-use. Plastic waste, more than 170 million tons in 2017 [2,3], and their additives, including butylated hydroxytoluene (BHT) or butylated hydroxyanisole (BHA), cause serious pollution problems, particularly in soil and water $[4,5]$. Therefore, extensive research has been conducted to replace common synthetic materials with natural ones [6]. The exploitation of natural materials in the preparation of eco-friendly packaging films has been a new promising issue for meat products safety [7].

Biodegradable films are being successfully used as active packaging in several processed foods, including seafood/meat products and fruits, as oxygen scavengers, barriers to water and light, antibacterial, and antibrowning agents [9]. The bio-based films made from natural polymers have recently attracted considerable interest because of their ecological properties, their safety, and their biodegradability in nature [10].

Natural polysaccharides, proteins, and lipids biopolymers are used for bio-based film preparation. Besides their role as a barrier against the external environment, they provide active functions by prolonging the shelf life and improving the safety and the sensory properties of different products [8]. In recent years, the exploitation of extracellular polymeric substances (EPS) has been of particular interest. However, EPS have not

\footnotetext{
* Corresponding author.

E-mail address: gongi.wejden@gmail.com (W. Gongi).
} 
yet been tested regarding the production of bioactive films nor as a packaging material [11].

EPS obtained from microalgae are versatile biopolymers produced at a high amount by several microalgae species, particularly thermophilic ones $[12,13]$.

In a previous work [13], results showed that Graesiella sp., is found amongst the most efficient EPSs producers reaching values close to $1.62 \mathrm{~g} \cdot \mathrm{L}^{-1}$ in laboratory cultures. The native Graesiella sp., EPS are hetero-sulphated polysaccharides of anionic nature composed mainly with polysaccharides $(80 \%)$ and proteins $(14 \%)$, presenting a high crystalline nature. They exhibited a high viscosity, emulsifying and flocculating proprieties. EPS have been utilized as additives, thickeners, emulsifiers, gelling agents, and stabilizers in several industrial sectors such as food products, pharmacy, petroleum industry, and bioremediation agents [14]. Furthermore, EPS provides high intrinsic bioactive properties such as antioxidant, anti-inflammatory, antiviral, antifungal, and antibacterial $[13,14]$ and therefore have a high potential for use as biodegradable active packaging, especially for meat products.

The present study aims to characterize an eco-friendly bioactive film using EPS extracted from the thermophilic microalga Graesiella sp., the EPS film was characterized according to its structure, optical and mechanical properties, thermal stability, water and oxygen barrier ability, and antioxidant potential.

Furthermore, we evaluated the shelf life of meat enrobed with the EPS film in terms of $\mathrm{pH}$, water activity, drip losses, color degradation, hemic iron, metmyoglobin, lipid and protein oxidation, and microbial stability, during nine days of preservation at $4 \pm 1{ }^{\circ} \mathrm{C}$.

\section{Material and methods}

\subsection{Strain and extracellular polymeric substances isolation}

The current research involved a thermophilic green microalga, Graesiella sp., (Chlorophyceae, Chlamydomonadales) obtained from the culture collection of algae at the National Institute of Marine Science and Technology (Tunisia) and preserved in the Spanish Bank of Algae with the code BEA1940B. The strain was isolated from a hot-spring $\left(60{ }^{\circ} \mathrm{C}\right.$; North of Tunisia at $\left.36^{\circ} 49^{\prime \prime} \mathrm{N}, 10^{\circ} 34^{\prime \prime} \mathrm{E}\right)$ and grown in Bold's Basal Medium (BBM) at a temperature of $30 \pm 1{ }^{\circ} \mathrm{C}$ and a light intensity of $120 \mu \mathrm{mol}$ photons $\mathrm{m}^{-2} \mathrm{~s}^{-1}$. Extracellular Polymeric Substances (EPS) were extracted from a stationary phase culture as described by Gongi et al. [13]. The recovered EPS solution was freeze-dried and stored in dark and dry conditions for edible film preparation.

\subsection{Film preparation}

Film-starting solutions were prepared by mixing crude EPS $(0.9 \mathrm{w} / \mathrm{v})$ and a plasticizer consisting of $0.1(\mathrm{w} / \mathrm{v})$ polyethylene glycol (PEG) 8000 (Sigma Chemical Co., St. Louis, MO, USA, Purity: $\geq 99.0 \%$ ) in distilled water.

The solution was homogenized in a water bath, stirred at 100 oscillations $\cdot \mathrm{min}^{-1}$ for $30 \mathrm{~min}$ at $40{ }^{\circ} \mathrm{C}$, and then clarified by sintered glass filtering. The filtered solution was spread over $6 \mathrm{~cm}$ Petri dishes $(30 \mathrm{~mL}$ per dish) and dried in a ventilated chamber at $30^{\circ} \mathrm{C}$. After drying, thin layers of EPS films were gently removed and conserved for further analysis.

\subsection{Film quality analysis}

\subsubsection{Thickness}

EPS-films thickness was measured at the center and at twenty other positions using a micrometer (Mitutoyo 547-312 s). An average value was calculated.

\subsubsection{Structural analysis}

Structural analysis of Graesiella sp., EPS film was performed by the
Fourier Transform Infrared spectroscopy (FTIR) analysis and the surface microstructure characterization using atomic force microscopy (AFM) and scanning electron microscopy (SEM).

FTIR spectra were obtained by pressing into a $16 \mathrm{~mm}$-diameter mold with a Perkin-Elmer spectrum GX FTIR system (Perkin-Elmer, USA) according to Gongi et al. [13].

EPS film AFM images were obtained by a multimode nanoscope IV (Digital Instruments, Santa Barbara, CA, USA) operating in the tapping mode regime, under ambient conditions. The images were analyzed using the software "Gwyddion".

The cross-section and top view morphology of Graesiella sp., EPS film samples were examined by SEM using an HR-FESEM SU-70 Hitachi microscope, operating at $4 \mathrm{kV}$ in the field emission mode and at an angle of $90^{\circ}$ with the surface, using different magnifications. Prior to imaging, film samples were cryo-fractured by immersion in liquid nitrogen and fixed on the SEM support using double side adhesive tape, and observed under an accelerating voltage of $5.0 \mathrm{kV}$ and an absolute pressure of $60 \mathrm{~Pa}$, after sputter coating with a $5 \mathrm{~nm}$ thick gold.

\subsubsection{Optical properties}

The EPS film-optical properties were assessed by light transmittance, color, and opacity measurements.

The EPS film transmittance (\%) was measured in UV/visible and IR spectrums using a spectrophotometer (Model 8451A, Hewlett-Packard Co., Santa Alara, CA, USA). A rectangular piece of film was cut and clamped between two magnetic cells and the transmittance was monitored at wavelength oscillating from 190 to $1200 \mathrm{~nm}$.

The color of the EPS film was determined in quadruplicate by a Color Flex spectro-colorimeter (Datacolor 800). The equation $\Delta \mathrm{E}^{*}=\left(\Delta \mathrm{L}^{* 2}+\Delta \mathrm{a}^{* 2}+\Delta \mathrm{b}^{* 2}\right)^{1 / 2}$ was used to evaluate the total color difference $\left(\Delta \mathrm{E}^{*}\right)$, where $\Delta \mathrm{L}^{*}, \Delta \mathrm{a}^{*}$ and $\Delta \mathrm{b}^{*}$ represent the differences between the corresponding color parameter of the sample and that of the white standard ( $\mathrm{L} 0^{*}=97.5, \mathrm{a} 0 *=-0.1$, and $\mathrm{b} 0 *=2.3$ ). The color scale ranged from $\mathrm{L}=0$ (black) to $\mathrm{L}=100$ (white), $-\mathrm{a}$ (green) to $+\mathrm{a}$ (red) and $-\mathrm{b}$ (blue) to $+\mathrm{b}$ (yellow).

EPS-film opacity was evaluated using a spectrophotometer (Model 8451A, Hewlett-Packard Co., Santa Clara, CA, USA) at a wavelength of $500 \mathrm{~nm}$. For each EPS sample, 4 rectangular pieces $(45 \times 10 \mathrm{~mm})$ were cut, then placed separately on the inner side of a $10 \mathrm{~mm}$ clear plastic cuvette, and the absorbance was measured. The opacities were calculated according to Gontard et al. [15]: Opacity = absorbance at $500 \mathrm{~nm} \times$ film thickness.

\subsubsection{Mechanical properties}

EPS films mechanical properties were assessed following the ASTMD882 [16] standard methods by measuring the tensile strength (TS) and the elongation at break (EAB) using a Testing Machine (Testometric, M350-5KN-CX). TS represents the maximum stress that a film can receive before breaking. $\mathrm{EAB}$ represents the film length increase (\%) prior to the film-break point. The films were cut into rectangular strips (50 mm length $\times 25 \mathrm{~mm}$ width) prior to analysis. Three samples were tested.

The breaking force and the breaking deformation of the films were also determined via the puncture force test $(\mathrm{N})$ using the same texture analyzer. EPS films placed in a $5 \mathrm{~cm}$ diameter cell were punched to the breaking point with a round-ended stainless-steel plunger $(3 \mathrm{~mm}$ in diameter) at a cross-head speed of $60 \mathrm{~mm} \cdot \mathrm{min}^{-1}$.

\subsubsection{Thermal properties}

Thermal properties of EPS films were characterized by differential scanning calorimetry (DSC) and thermogravimetric analysis (TGA).

DSC measurements $(n=3)$ were completed by a differential scanning calorimeter Mettler Toledo Star (TA Instruments - TA Q100). About $6 \mathrm{mg}$ of EPS films were exposed to pre-heating from 25 to $120{ }^{\circ} \mathrm{C}$, then reheated to $120{ }^{\circ} \mathrm{C}$ or $280{ }^{\circ} \mathrm{C}$ (rate: $5{ }^{\circ} \mathrm{C} \cdot \mathrm{min}^{-1}$, nitrogen flow: $50 \mathrm{~mL} \cdot \mathrm{min}^{-1}$ ). Using the DSC curve, glass transition temperature and 
enthalpy were recorded from the minimum of the first derivative and the smallest peak.

TGA of EPS films ( $n=3)$ was carried out using a Thermogravimetric Analyzer SETSYS Setaram (TA Instruments - TA Q100). Analysis was made at a temperature varying from 0 to $800{ }^{\circ} \mathrm{C}$ at a rate warming of $10^{\circ} \mathrm{C} \cdot \mathrm{min}^{-1}$. An inert atmosphere was obtained by using nitrogen as a purge gas (flow rate: $50 \mathrm{~mL} \cdot \mathrm{min}^{-1}$ ). The strips testing area was $25 \mathrm{~mm}^{2}$.

\subsubsection{Behavior with respect to water and oxygen}

The behavior of EPS film with respect to water and oxygen were characterized by measuring the water indexes (water content and swelling degree) and the film barrier properties (oxygen and water vapor permeability).

Water content and swelling degree of Graesiella sp., EPS films were determined according to Pastor et al. [17] and Peng and Li [18], respectively. The films were cut into rectangles $(2 \times 2 \mathrm{~cm})$ and weighed to get the initial weight (M1) then dried in a vacuum oven at $70{ }^{\circ} \mathrm{C}$ for $24 \mathrm{~h}$ to determine the dry mass (M2). After that, EPS films were soaked in a Petri dish containing $30 \mathrm{~mL}$ of distilled water and stored for $24 \mathrm{~h}$ at room temperature $\left(25 \pm 2{ }^{\circ} \mathrm{C}\right.$ ). The remaining water (not absorbed by film samples) was discarded and EPS films were dried with filter paper and weighed (M3). Three measurements were taken for each film sample to calculate the average value of the water content and the swelling degree by the Eqs. (1) and (2):

Water content $(\%)=\frac{M 1-M 2}{M 1} \times 100$

Degree of swelling $(\%)=\frac{M 3-M 2}{M 2} \times 100$

Oxygen permeability (OP) of the EPS films was evaluated using a TestTex Permeability Tester (TF164) following ASTM standard test method D3985-05 [19]. Testing was conducted with three samples at a temperature of $25{ }^{\circ} \mathrm{C}$ in a dry environment $(0 \% \mathrm{RH})$.

The water vapor permeability was performed according to the ASTM method [20] under controlled conditions of humidity (50 $\pm 5 \% \mathrm{RH})$ and temperature $\left(23 \pm 2{ }^{\circ} \mathrm{C}\right)$. Three replicates were monitored.

\subsection{Antioxidant activity}

Graesiella sp., EPS film was evaluated for its total antioxidant capacity (TAC) [21], $\beta$-carotene bleaching assay [22], and DPPH scavenging activity [23] at concentrations ranging from 20 to $150 \mathrm{~g} \cdot \mathrm{L}^{-1}$. Iron reducing power was determined at levels ranging from 0 to $300 \mathrm{~g} \cdot \mathrm{L}^{-1}$ [24] and metal chelating activities at concentrations varying from 0 to $100 \mathrm{~g} \cdot \mathrm{L}^{-1}$ [25]. L-Ascorbic acid (Sigma Aldrich, CAS Number 50-81-7; Purity $=99 \%, 10 \mathrm{~g} \cdot \mathrm{L}^{-1}$ ), was used for the antioxidant activity comparison. Three replicates were used for each test.

\subsection{Beef preservation with Graesiella sp., extracellular polymeric substances film}

Beef meat was provided by a commercial company and initial analyses were performed after $8 \mathrm{~h}$ after slaughter. Samples were cut into small portions $(5 \mathrm{~cm} \times 5 \mathrm{~cm} \times 2 \mathrm{~cm})$ and then divided into two batches of eighteen pieces each. The first batch represented meat portions packed in the EPS films (EPS-packed). The second batch was formed by meat portions packed with a food plastic wrap made out of Polyvinylchloride (PVC), commonly used in the preservation of meat in department stores (PVC-packed). Both batches were stored at $4 \pm 1{ }^{\circ} \mathrm{C}$ for 9 days. The post-mortem states of meat samples, packed with EPS film and packed with PVC film were evaluated in triplicate by measuring $\mathrm{pH}$, water activity, drip losses, metmyoglobin level, color, hemic iron malondialdehyde (MDA), and Total Basic Volatile Nitrogen (TBV-N) contents.

Microbiological state evolution was also determined by quantifying the total vital counts and Pseudomonas bacteria. Measurements were performed at days 0 (initial), 3, 6, and 9 of cold storage.

The $\mathrm{pH}$ was determined following the normalized method (ISO 2917). Water activity (aw) was performed using Novasina Lab swift water activity equipment after calibrating the system with aw values reference points $(0.11,0.33,0.58,0.75,0.88$, and 0.99$)$.

Drip Loss represented the difference in meat weight measured at the beginning and the end of the storage period and expressed as a percentage of the initial as described by Allen et al. [26]. Metmyoglobin content (Mmb) was determined following the method described by Krzywicki [27]. Each sample ( $5 \mathrm{~g}$ ) was cold mixed $\left(4 \pm 1^{\circ} \mathrm{C}\right)$ with $50 \mathrm{ml}$ of phosphate buffer ( $40 \mathrm{mM}$, pH 6.8) for $15 \mathrm{~min}$ and then centrifuged for $30 \mathrm{~min}$ ( $4000 \mathrm{rpm}, \mathrm{T}: 4 \pm 1{ }^{\circ} \mathrm{C}$ ). The recovered supernatant was clarified by filtration on glass wool. The absorbance of the filtrates was determined at 3 different wavelengths, 525, 572 , and $730 \mathrm{~nm}$. The rate of $\mathrm{Mmb}$ in meat samples was determined according to Eq. (3):

$\operatorname{Mmb}(\%)=1.395-\left(\left(\mathrm{A}_{572}-\mathrm{A}_{730}\right) /\left(\mathrm{A}_{525}-\mathrm{A}_{730}\right)\right) \times 100$.

The color of meat samples during the storage period was determined using a Color Flex spectro colorimeter (data color). Measurements were performed in quadruplicate.

The heme iron level was carried out according to Clark et al. [28]. Two grams of meat were mixed with $9 \mathrm{ml}$ of acidified acetone $(90 \%$ acetone ( $>99.5 \%$ purity), $8 \%$ deionized water, $2 \% \mathrm{HCl}(90 \%$ purity)). After incubation for $1 \mathrm{~h}$ at $25{ }^{\circ} \mathrm{C}$ in the dark, the mixture was filtered using glass wool. The concentration of heme iron in the filtrate was calculated by Eq. (4) using absorbance at $640 \mathrm{~nm}$.

Heme iron $\left(\mu \mathrm{g} \cdot \mathrm{g}^{-1}\right.$ of meat $)=\mathrm{A}_{640} \times 680 \times 0.0882$

Malondialdehyde (MDA) was derivatized with thiobarbituric acid (TBA) to evaluate the level of lipid oxidation [29]. Thus, $375 \mu \mathrm{L}$ of a solution of ground meat were mixed with $150 \mu \mathrm{L}$ of buffer $(50 \mathrm{mM}$ Tris, $150 \mathrm{mM} \mathrm{NaCl}, \mathrm{pH} 7.4$ ) and $375 \mu \mathrm{L}$ of $1 \%$ BHA dissolved in $20 \%$ hot TCA ( $>99.5 \%$ purity) and then, centrifuged for $10 \mathrm{~min}$ at $1000 \mathrm{rpm}$. Finally, $80 \mu \mathrm{l}$ of $\mathrm{HCl}(>99.5 \%$ purity) $(0.6 \mathrm{M})$ and $320 \mu \mathrm{L}$ TBA ( $>99.5 \%$ purity) (26 mMTris - $120 \mathrm{mM} \mathrm{TBA}$ ) were added to the supernatant $(400 \mu \mathrm{L})$ and incubated at $80{ }^{\circ} \mathrm{C}$ for $10 \mathrm{~min}$. Absorbance measurements were carried out at $530 \mathrm{~nm}$. The concentration of the complex (TBA-MDA) formed is proportional to the content of MDA.

Total Volatile Basic Nitrogen (TVB-N) content of meat was measured by steam distillation based on the Chinese standard method (GB/T 5009.44.40).

Microbiological analysis of meat at each sampling interval was investigated in triplicates according to Datta et al. [30]. Portions of $10 \mathrm{~g}$ of packed and control samples were homogenized for $1 \mathrm{~min}$ in sterile diluent (Merck, Darmstadt, Germany) using a Seward stomacher. For total viable counts (TVC) counting, appropriate serial dilutions $(1 / 10$, $1 / 100,1 / 1000$ ) were spread on prepared Petri dishes using Plate Count Agar (PCA; Merck, Darmstadt, Germany). Glutamate Starch Phenol Red agar (GSP, Merck, Darmstadt, Germany) was used for Pseudomonas bacteria counting. All plates were incubated at $28-30{ }^{\circ} \mathrm{C}$ for $48 \mathrm{~h}$. Bacterial counts were expressed as $\log 10$ counts forming units CFU. $\mathrm{g}^{-1}$ sample.

\subsection{Statistical analyzes}

Statistical analyzes were performed with SPSS ver. 20.0 professional edition. Changes between treatments were evaluated with Student's $t$ test and the $p$-values $<0.05$ were considered to be statistically significant.

\section{Results and discussion}

Present results show that EPS from Graesiella sp., have a good filmforming capacity, by adding only $10 \%$ (w/w of EPS) of the plasticizing 
agent polyethylene glycol (PEG).

The thickness value (Table 1) of the Graesiella sp., EPS film was $0.22 \mathrm{~mm}$, considered appropriate for potential use as natural packaging [31]. This value is within the range of usual commercial films (less than $0.3 \mathrm{~mm}$ ) [31] and higher than other biological origin films that range from 42 to $67 \mu \mathrm{m}[32,33]$. The thickness of the film depends on the concentration of the plasticizer, its type, and its solubility. Thinner films are required for industrial uses. Indeed, thinner films impart flexibility, reduce brittleness, improve impact tear-resistance and regulate the flow of coating material $[9,11]$.

Plasticizers are generally required for hydrocolloid film-forming preparations and their amount varies between $10 \%$ and $60 \%$ by weight of the hydrocolloid [31]. These acts by increasing the free volume or by decreasing intermolecular attractions between adjacent polymeric chains, reducing hydrogen bonding [31]. In the context of this work, several other types of plasticizers such as glycerol and sorbitol have been previously tested with less satisfactory results (data not shown).

\subsection{Structural analysis}

FT-IR spectroscopy of Graesiella sp., EPS film (Fig. 1) shows little change in functional groups with respect to Graesiella sp., native EPS [13]. Broadband between 2900 and $3000 \mathrm{~cm}^{-1}$ resulted from the $\mathrm{C}-\mathrm{O}$ and $\mathrm{C}=\mathrm{O}$ stretching vibrations (carboxylates function) typical from the hydroxyl functionality of carbohydrates [34]. A strong band at the region $1000 \mathrm{~cm}^{-1}$ was identified, corresponding to the polyethylene glycol (-OH group) added as a plasticizer [35]. In addition, amide peaks at the wavelength range of $1600 \mathrm{~cm}^{-1}$ were recorded indicating the presence of proteins/peptides in Graesiella sp., EPS film [36].

The Tapping-mode of AFM images yielded information about the surface features as well as the homogeneity of the EPS film (Fig. 2a). The surface topography of EPS films showed low roughness $(5.5 \mathrm{~nm})$ and was homogenous and continuous without pores or cracks suggesting good structural integrity. The 3D images (Fig. 2b) showed a flat and compact structure with scattered small particles having peaks of $1 \mu \mathrm{m}$ heights.

SEM micrographs yield information about the film internal microstructures. The SEM top view and cross-section (Fig.3) confirmed the homogeneous character and revealed a microstructural lamellar arrangement of the EPS film.

Regarding the homogenous and compact structural, the surface morphology of the EPS had similar features to that of magnetic nanocomposite (GO/ZIF-8/ $\gamma$-AlOOH) based on graphene oxide $[37,38]$.

\subsection{Optical properties}

In food packaging, film transparency is a critical attribute, especially if the film is used at the surface of packed food or if it is intended to improve product appearance. Graesiella sp., EPS film showed high

Table 1

Physical, mechanical, and differential scanning calorimetry properties of Graesiella Extracellular Polymeric Substances (EPS) film.

\begin{tabular}{lll}
\hline EPS film properties & & Mean \pm SD \\
\hline Physical & Thickness (mm) & $0.221 \pm 0.001$ \\
& Oxygen permeability (SI) & $0.008 \pm 0.001$ \\
\multirow{3}{*}{ Mechanical } & Water vapor permeability (SI) & $0.038 \pm 0.006$ \\
& Tensile strength (MPa) & $16.25 \pm 0.03$ \\
\multirow{2}{*}{ Thermal } & Elongation at break (\%) & $4.98 \pm 0.09$ \\
& Puncture force (N) & $25.16 \pm 0.08$ \\
$\Delta \mathrm{E}^{*}$ & Transition temperature $\left({ }^{\circ} \mathrm{C}\right)$ & $126.15 \pm 2.00$ \\
& Transition enthalpy $\left({ }^{\circ} \mathrm{C}\right)$ & $243.17 \pm 1.00$ \\
\hline
\end{tabular}

EPS: Extracellular Polymeric Substances; mm: Millimeters; SI: International System of Units; MPa: Megapascals; N: Newtons; $\Delta \mathrm{E}^{*}$ : Difference in color. Values are given as mean $(n=3) \pm$ standard deviation.

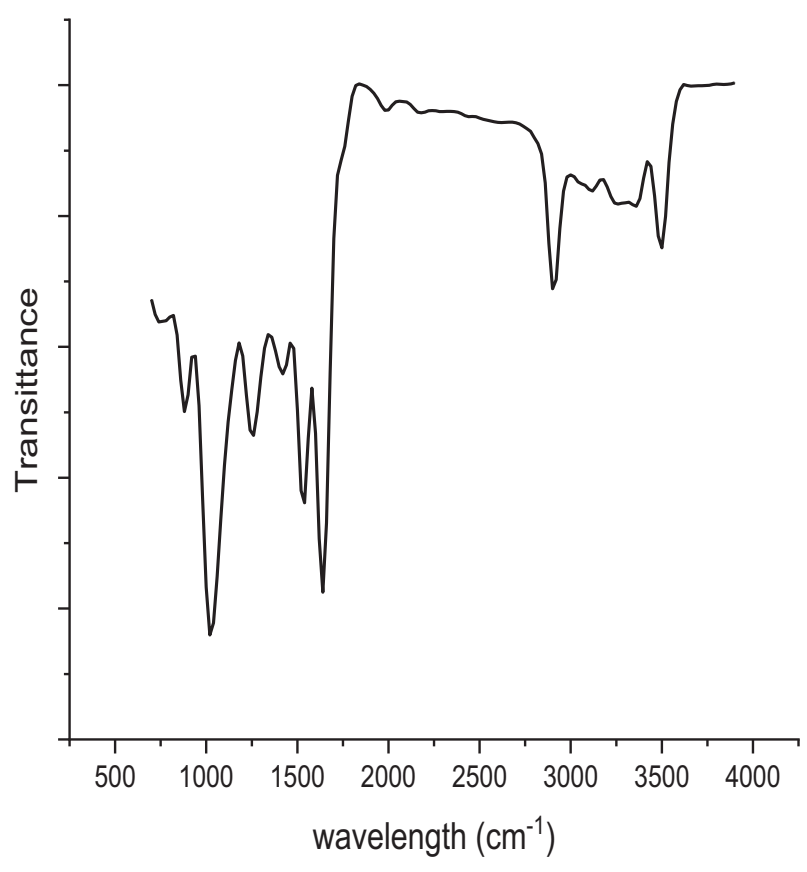

Fig. 1. Infrared spectrum of Graesiella EPS film recorded in the region of $4000-500 \mathrm{~cm}^{-1}$.

transparency with an opacity value lower than $0.05 \pm 0.01$. The transparency of EPS film could be related to its low lipid content [31]. Higher levels of lipid content increase the opacity of biofilms [39].

In addition, Graesiella sp., EPS film showed a high level of lightness $\left(L^{*}=92.51 \pm 0.10\right)$ with a tendency towards a yellowish color $\left(b^{*}=5.82 \pm 0.05\right)$, characteristic of scytonemin and mycosporine-like amino acids, usually present in microalgae EPS [40]. The difference in color $\left(\Delta \mathrm{E}^{*}\right)$ was used to infer if the color is detectable by the human eyes. Wang et al. [41] demonstrated that an $\Delta \mathrm{E}^{*}$ value of 1.6 was the lowest value of material color detection by the consumer. The Graesiella sp., EPS film shows an $\Delta \mathrm{E}^{*}$ value of $4.28 \pm 0.09$ (Table 1), which is considered detectable.

The optical transmittance spectrum of the Graesiella sp., EPS film (Fig. 4) showed strong light transmittance in the region of the visible radiation $(400-780 \mathrm{~nm})$ with a maximum observed at $780 \mathrm{~nm}$. Strong transmission bands were also detected in the IR-A region $(892-900 \mathrm{~nm}$ ) with the absence of transmission of the long wavelengths' radiations in the IR-C region (1023 to 1100). The Graesiella sp., EPS films form a barrier preventing the transmission of short-wavelength radiations, with zero transmission of UV-B radiations (190-200 nm) and weak transmittance in the UV-A region (220 to $240 \mathrm{~nm}$ ). This gives a sunscreen protective effect, which could be related to the richness of microalga EPS in UV-absorbing compounds [40]. It is effectively well known that short and energetic UV radiations are key mediators of reactive oxygen species (ROS) causing oxidative cell damage through peroxidation of membrane lipids [42], which accelerates fat photo-oxidation, rancidity, and discoloration $[33,43]$. EPSs film could be applied as transparent packaging films providing sufficient light protection to light-sensitive food products including meat.

\subsection{Mechanical properties}

Suitable mechanical strength and elasticity are generally required for packaging film $[17,18]$. The tensile strength of Graesiella sp., EPS film was $16.25 \pm 0.03 \mathrm{MPa}$ (Table 1 ). The obtained value is in the low range of common biological films (10-100 MPa) and synthetic ones (9-60 MPa) $[44,45]$. Furthermore, the mean elongation at break of the Graesiella sp., EPS film was $4.98 \pm 0.09 \%$ (Table 1), which is weaker 


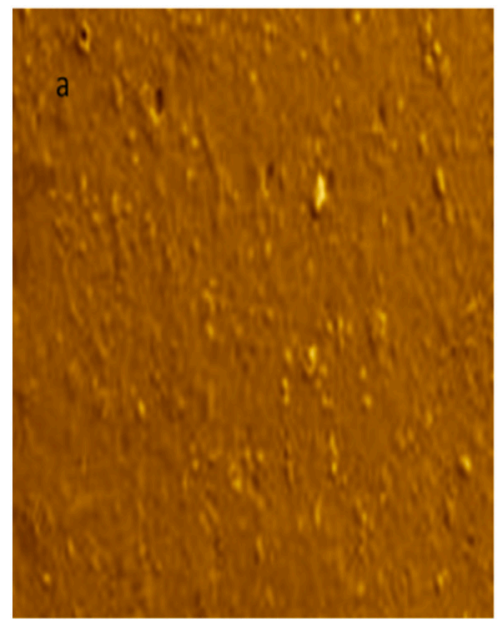

b

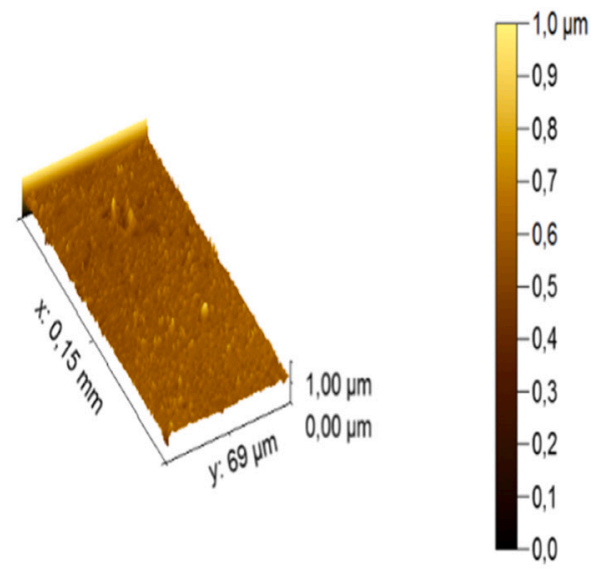

Fig. 2. Atomic force microscopy topographic images of EPS film (a) and its three-dimensional image (b).

$$
\text { Top- View }
$$

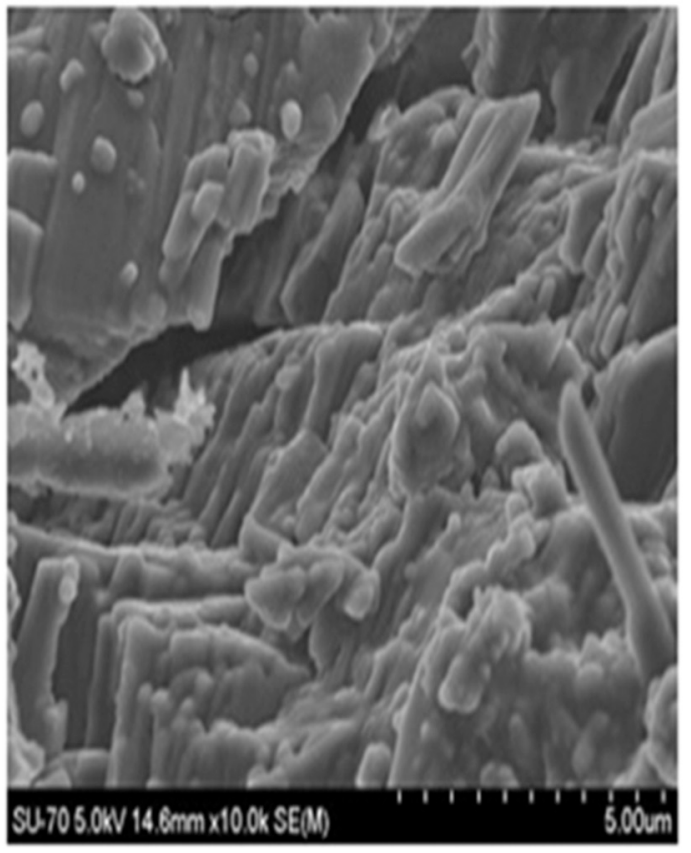

Cross-section

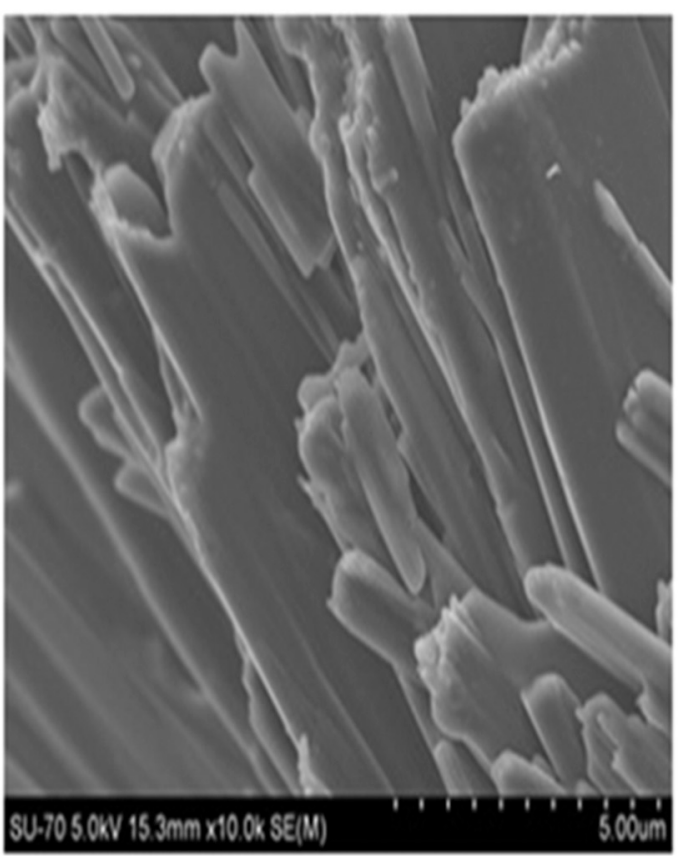

Fig. 3. Scanning electron microscope micrographs of cross-section and top view of EPS films observed under an accelerating voltage of $5.0 \mathrm{kV}$ and an absolute pressure of $60 \mathrm{~Pa}$.

than $\mathrm{EAB}$ values recorded with synthetic ones, indicating a relative mechanically fragility of Graesiella sp., EPS film $[44,45]$.

However, the puncture force of EPS film, $25.16 \pm 0.08 \mathrm{~N}$, is higher than those recorded for other biofilms with puncture force not exceeding $15 \mathrm{~N}$ [46]. Thus, a higher force is needed to punch through the EPS film membranes indicating that EPS film presented a rigid bonding and a compact molecular structure [47].

\subsection{Thermal properties}

DSC results revealed that Graesiella sp., EPS film did not show any melting event within the tested temperature range $\left(25\right.$ to $\left.250{ }^{\circ} \mathrm{C}\right)$. The transition temperature and transition enthalpy were 126 and $243{ }^{\circ} \mathrm{C}$ respectively (Table 1 ), indicating strong thermal stability.

Commonly at least two main degradation steps are observed in biological and synthetic films; (i) film dehydration and (ii) film components decomposition [48] which was detected by inflection point in the TGA curves. The TGA curves of Graesiella sp., EPS film showed a single stage of degradation process in the experimented temperature interval (200 to $800{ }^{\circ} \mathrm{C}$ ) (Fig. 5), related to strong thermal stability. Therefore, the high degree of crystallinity of Graesiella sp., EPS [13] strengthens the intermolecular bonds and thus increases the stability of EPS film against high temperatures [49]. 


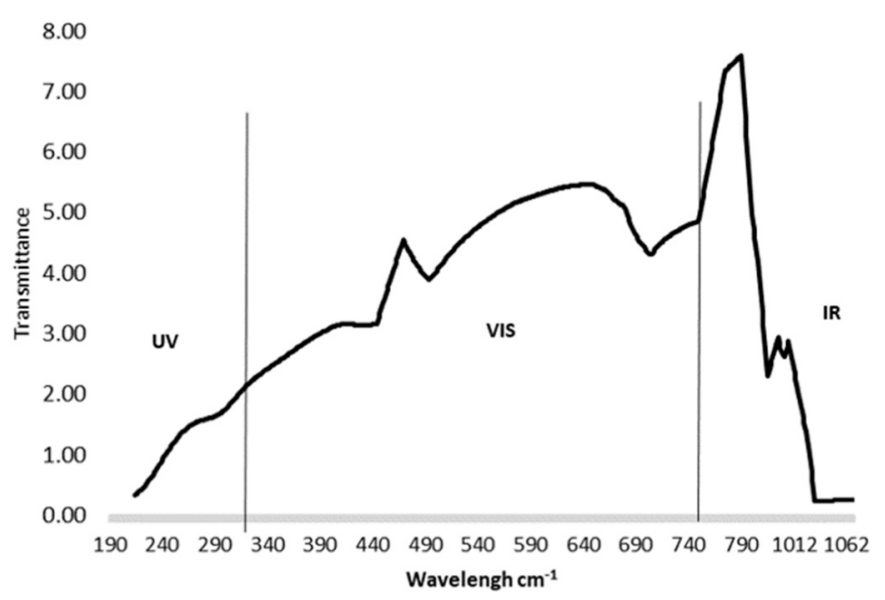

Fig. 4. Light transmittance spectra of Graesiella EPS film in the ultraviolet, visible and infrared regions presented as wavelengths floating average with a period of 25. UV: ultraviolet; Vis: visible; IR: infrared.

\subsection{Behavior with respect to water and oxygen}

Graesiella sp., EPS film presented low values for water content $(13.71 \pm 1.52 \%)$ and of swelling degree $(14.42 \pm 3.51 \%)$ when compared to other biological biofilms [50]. These lower values indicate a higher cross linkage interaction that could be related to the higher crystalline nature of Graesiella sp., EPS [13] which reduces the number of hydrogen bonds to water [18].

On the other hand, EPS film water vapor barrier (WVP) of $0.038 \pm 0.006$ SI (Table 1 ) was lower than that's of other biological films and traditional packaging material $(0.96$ to $100 \mathrm{SI})[32,33,52]$ indicating a lower amount of water vapor passing through the film membrane [52]. Such characteristic is important to extend the expiration date of food especially by limiting the bacterial proliferation and the transfer of moisture through the film [53].

Oxygen barrier property plays an essential role in food preservation. The oxygen permeability of the Graesiella sp., EPS film was evaluated at $0.008 \pm 0.01 \mathrm{SI}$ (Table 1). This value is lower than that reported for the common polyvinylidene chlorides (PVDC) and ethylene-vinyl alcohol copolymer films where water vapor permeability values are in the range of 1 to 10 SI [32,50], indicating higher efficiency of Graesiella sp., EPS film as packaging materials, limiting contamination by microorganisms and lipid oxidation $[9,44]$.

\subsection{Antioxidant activity}

Different methods are commonly used to assess product antioxidant activities that implicate either direct or indirect determination of the level/extent of formation/decrease of free radicals. For the aim to characterize the different mechanisms of action of EPS film the in vitro antioxidant ability was evaluated by the total antioxidant capacity (TAC) (Fig.6), the DPPH free radical scavenging, the $\beta$-carotene bleaching assay, the iron-reducing power, and the metal chelating ability (Fig. 7) and compared to $L$-ascorbic acid which was used as a positive control. To our knowledge, this is the first report about the capacity to produce films with an antioxidant capacity based on the microalgal EPS.

TAC evaluated by the reduction of Mo (VI) to Mo (V) for both EPS film and $L$-ascorbic acid, was observed as dose-dependent. Compared to $L$-ascorbic acid, EPS film exhibited a significantly lower antioxidant ability at all tested concentrations. At a concentration of $200 \mathrm{mg} \cdot \mathrm{mL}^{-1}$, the TAC of EPS film $\left(\mathrm{A}_{695}=2.40 \pm 0.12\right)$ was $40 \%$ lower than that obtained by $L$-ascorbic acid $\left(\mathrm{A}_{695}=3.00 \pm 0.02\right)$. Therefore, these findings suggest that Graesiella EPS film could react with Mo (VI) to convert it to more stable molecules, Mo (V), by donating electrons.

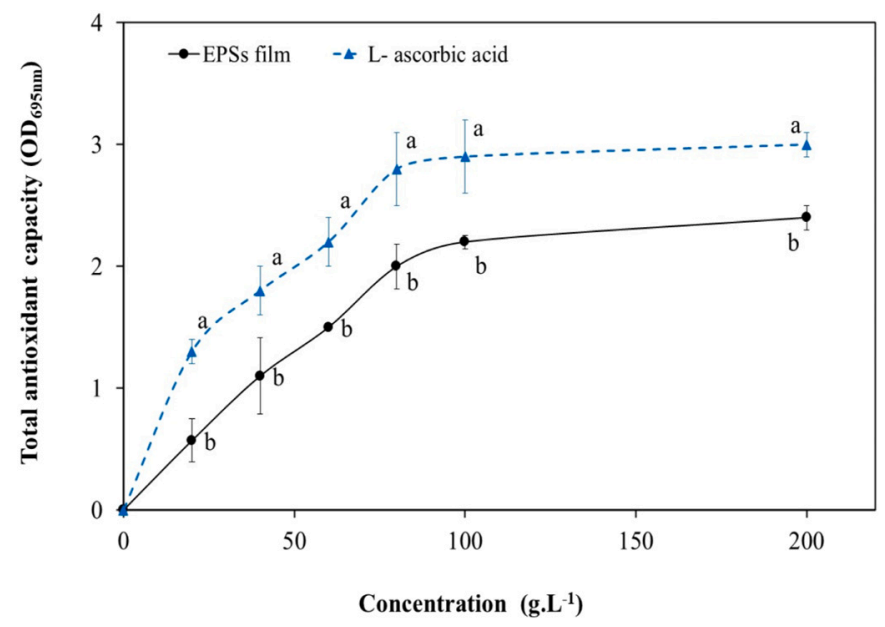

Fig. 6. Total antioxidant capacity $\left(\mathrm{OD}_{695 \mathrm{~nm}}\right)$ of the Graesiella EPS film and $L^{-}$ ascorbic acid, at different concentrations. Values are expressed as the mean of triplicate measurements $(n=3 ; \pm S D$ ). Different letters specify significant differences between concentrations $(p<0.05)$.

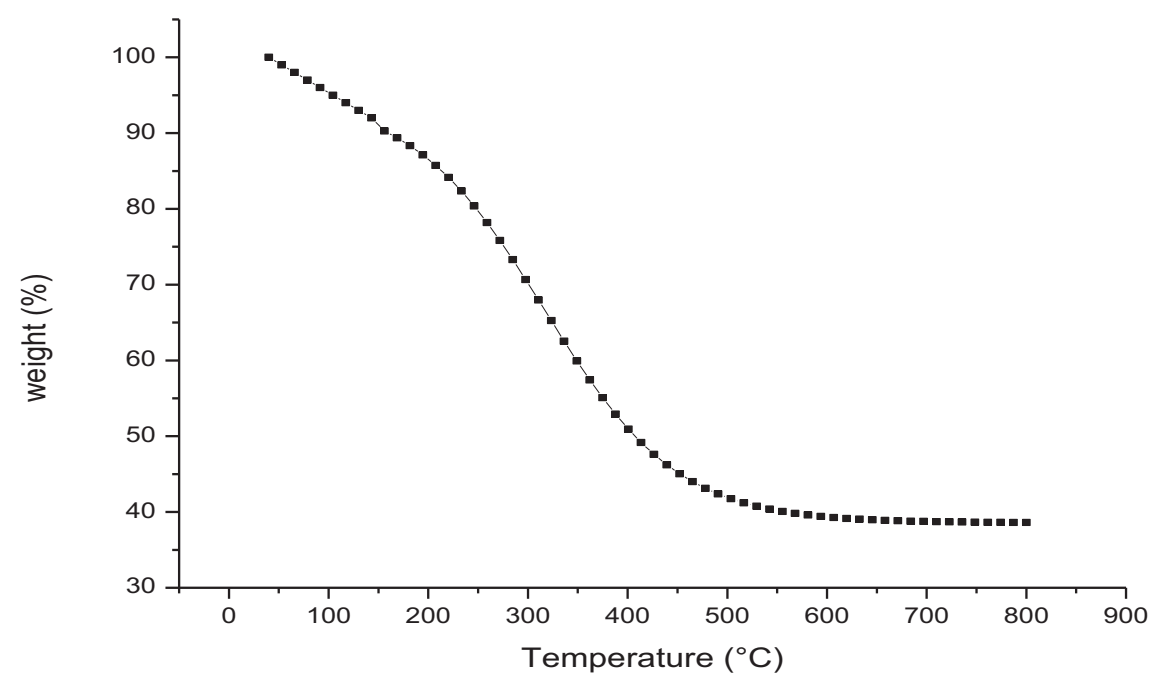

Fig. 5. Thermogravimetric analysis of Graesiella EPS film. 
a
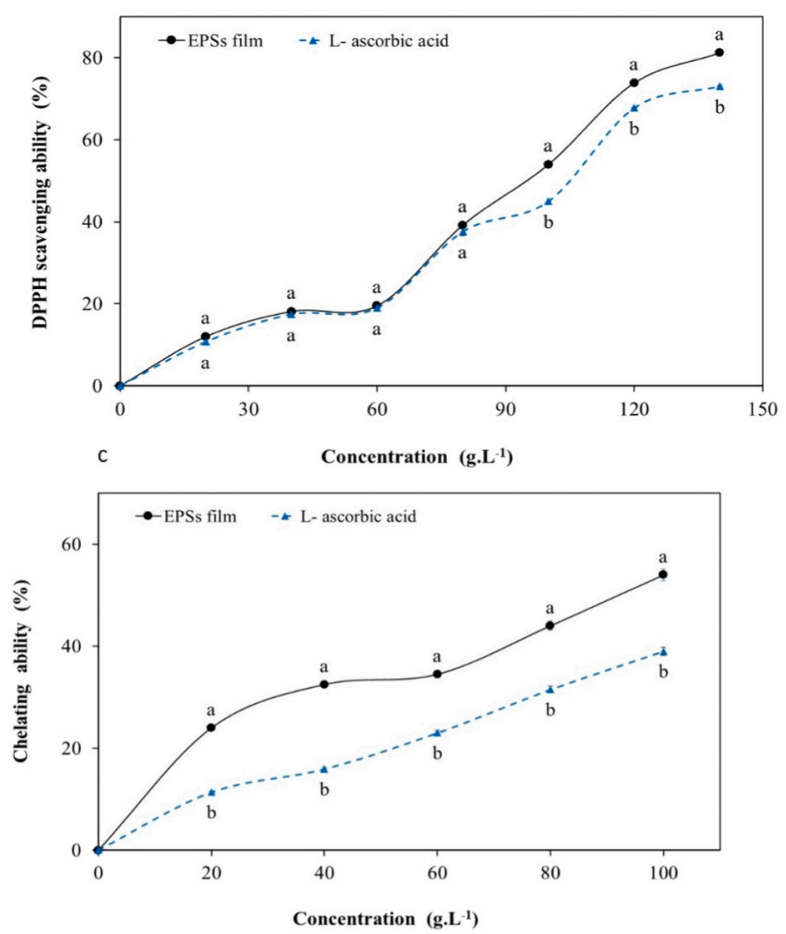
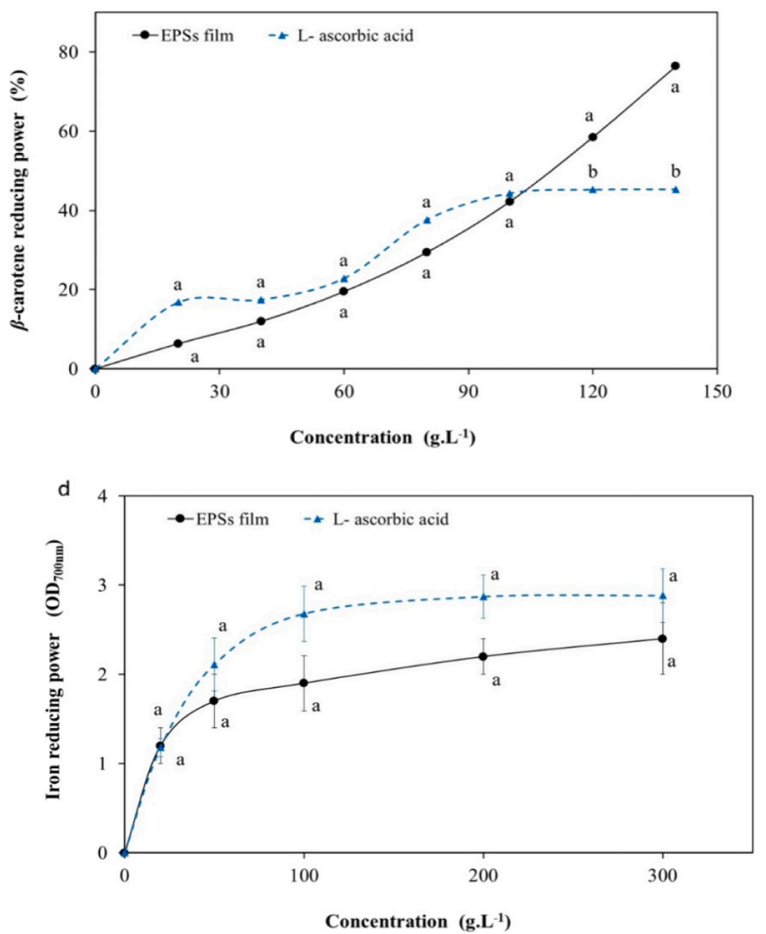

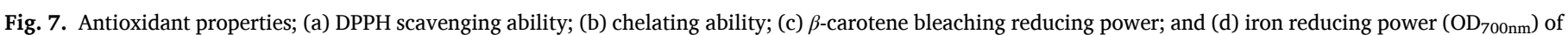

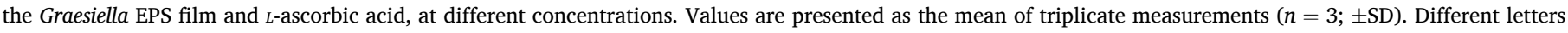
specify significant differences between concentrations $(p<0.05)$.

In addition, EPS film showed a high radical scavenging ability. DPPH free radical scavenging test (Fig. 7a) showed that both EPS film and $L^{-}$ ascorbic acid exhibited similar potential at low concentrations (20 $\mathrm{mg} \cdot \mathrm{mL}^{-1}$ to $80 \mathrm{mg} \cdot \mathrm{mL}^{-1}$ ). At the highest tested concentration $\left(150 \mathrm{mg} \cdot \mathrm{mL}^{-1}\right)$ EPS film displayed a significantly higher DPPH scavenging activity ( $84 \pm 0.06 \%)$ compared to $L$-ascorbic acid $(69 \pm 0.05 \%)$. Furthermore, EPS film showed a significantly higher $\beta$-carotene bleaching reduction effect (Fig. $7 \mathrm{~b}$ ), reaching $80 \pm 0.03 \%$ at a level of $150 \mathrm{mg} \cdot \mathrm{mL}^{-1}$, while the bleaching reduction ability of $L$-ascorbic acid was only $45 \pm 0.01 \%$ at the same concentration. Our results highlighted a strong scavenging ability when compared to other biological films, based on marine macroalgae polymers, with the highest scavenging percentage did not exceed $60 \%$ [54].

The potent DPPH scavenging ability of EPS is related to its weak dissociation energy of the polysaccharide $\mathrm{O}-\mathrm{H}$ bond that gives EPS high potential to donate $\mathrm{H}^{\bullet}$ implied in the stabilization of free radicals $[55,56]$. The hydrogen donating ability was identified to be the dominant antioxidant property of EPS obtained from bacterial strains [57].

The reduction ability of iron $\left(\mathrm{Fe}^{3+}\right)$ to its ferrous form $\left(\mathrm{Fe}^{2+}\right)$ in the presence of EPS film solution, was monitored by UV spectrophotometry at an absorbance of $700 \mathrm{~nm}$. The present study (Fig. 7c) presents a lower iron reducing power of EPS than $L$-ascorbic acid at all tested concentrations. Maximum iron reducing power of EPS film $\left(\mathrm{OD}_{700}=2.4 \pm 0.4\right.$ at $\left.300 \mathrm{mg} \cdot \mathrm{mL}^{-1}\right)$ was slightly lower $(p<0.05)$ than that recorded with $L^{-}$ ascorbic acid $\left(\mathrm{OD}_{700}=2.8 \pm 0.3\right.$ at $\left.300 \mathrm{mg} \cdot \mathrm{mL}^{-1}\right)$. Graesiella sp., EPS film iron-reducing power value was higher than those recorded in the case of other biological films $[33,51]$.

However, the ability of EPS films as a ferrous-chelating agent, expressed as a percentage of $\mathrm{Fe}^{2+}$-chelating ability (Fig. 7d), was significantly higher than $L$-ascorbic acid; $0-55 \%$ for EPS film while to $L^{-}$ ascorbic acid was from 0 to $35 \%$. Ferric form $\left(\mathrm{Fe}^{3+}\right)$ presents low bioavailability in the organism and is the major catalyst of lipid oxidation [58]. To be absorbed, iron must be in the ferrous $\left(\mathrm{Fe}^{2+}\right)$ state. Iron chelators are involved in mobilizing iron in its ferrous states $\left(\mathrm{Fe}^{2+}\right)$ by forming soluble and stable complexes and limiting its ability to transfer single electrons which inhibit free radicals' formation [59]. EPS are well known for the binding and chelating capacity of several metal ions [60]. High iron-chelating activity has been also identified for several cyanobacteria EPS, leading to the decrease of oxidation state and the suppression of the metal oxidant effects [61].

The microalgal EPS antioxidant activity has been largely reported and is mainly attributed to its sulfated nature [14]. Thus, EPS film as a food packaging material can avoid oxidative degradation that causes lipid rancidity and thus enhance food preservation [9,44].

\subsection{Meat samples preservation}

In this work, beef meat samples were wrapped using $10 \times 10 \mathrm{~cm}$ EPS films and compared to meat packed with PVC films and stored for 9 days at $4 \pm 1{ }^{\circ} \mathrm{C}$. PVC films, present high oxygen and UV light permeabilities [51]. According to Coma [9], the shelf life of meat stocked at $4{ }^{\circ} \mathrm{C}$ in the market is commonly short, up to five days as a maximum. Thus, the nine days used in this study represent a relatively long storage period.

The $\mathrm{pH}$ of muscle tissue during the storage is commonly considered as an indicator of meat quality evolution [62]. Typically, the transformation of muscle into meat is accompanied by the breakdown of glycogen into lactic acid, and the rate and extent of postmortem $\mathrm{pH}$ decrease. In our conditions (Table 2), the $\mathrm{pH}$ value of meat packed with EPS indicated a $\mathrm{pH}$ meat stability $(5.85 \pm 0.01)$ even after 9 days of storage, remaining within the range of high quality of meat [63] while PVC-packed meat samples showed a $\mathrm{pH}$ increase $(\mathrm{pH}=6.12 \pm 0.00)$ since the third day of storage. The increase of $\mathrm{pH}$ in PVC-packed meat samples might be due to the accumulation of basic compounds derived from the growth of Pseudomonas spp., and also to the decomposition of proteins and production of alkaline substances such as amines [64].

It is well established that a rapid $\mathrm{pH}$ increase during the postmortem phase may induce protein denaturation, with adverse consequences on the water-holding capacity and drip loss [65]. In the present study, the 
Table 2

Nutritive and safe quality parameters of polyvinylchloride (PVC) and Graesiella Extracellular Polymeric Substances (EPS) packed meat during 9 days of storage.

\begin{tabular}{|c|c|c|c|c|c|}
\hline \multirow[t]{2}{*}{ Parameter } & & \multicolumn{4}{|l|}{ Storage days } \\
\hline & & 0 & 3 & 6 & 9 \\
\hline \multirow[t]{2}{*}{$\mathrm{pH}$} & PVC-packed & $5.87 \pm 0.02^{(a)}$ & $6.02 \pm 0.01^{(b)}$ & $6.12 \pm 0.00^{(\mathrm{b})}$ & $6.19 \pm 0.00^{(\mathrm{b})}$ \\
\hline & EPS-packed & & $5.86 \pm 0.00^{(\mathrm{a})}$ & $5.85 \pm 0.01^{(a)}$ & $5.85 \pm 0.01^{(a)}$ \\
\hline \multirow[t]{2}{*}{ Water activity } & PVC-packed & $0.89 \pm 0.00^{(a)}$ & $0.94 \pm 0.00^{(\mathrm{b})}$ & $0.95 \pm 0.00^{(\mathrm{c})}$ & $0.95 \pm 0.01^{(\mathrm{c})}$ \\
\hline & EPS-packed & & $0.89 \pm 0.00^{(\mathrm{a})}$ & $0.87 \pm 0.00^{(\mathrm{d})}$ & $0.87 \pm 0.00^{(\mathrm{d})}$ \\
\hline \multirow[t]{2}{*}{ Drip loss (\%) } & PVC-packed & $0.00 \pm 0.00^{\text {(a) }}$ & $11.0 \pm 1.0^{(\mathrm{b})}$ & $18.0 \pm 2.0^{(\mathrm{d})}$ & $23.0 \pm 4.0^{(\mathrm{d})}$ \\
\hline & EPS-packed & & $2.0 \pm 0.4^{(\mathrm{c})}$ & $9.0 \pm 0.6^{(\mathrm{e})}$ & $9.0 \pm 0.6^{(\mathrm{e})}$ \\
\hline \multirow[t]{2}{*}{ Pseudomonas (CFU.g ${ }^{-1}$ ) } & PVC-packed & $2.03 \pm 0.011^{\text {(a) }}$ & $4.83 \pm 0.01^{(b)}$ & $5.2 \pm 0.02^{(\mathrm{d})}$ & $6.9 \pm 0.03^{(\mathrm{e})}$ \\
\hline & EPS-packed & & $3.11 \pm 0.01^{(\mathrm{c})}$ & $3.91 \pm 0.11^{(\mathrm{e})}$ & $4.01 \pm 0.21^{(\mathrm{e})}$ \\
\hline \multirow[t]{2}{*}{ Total viable counts (CFU. $\mathrm{g}^{-1}$ ) } & PVC-packed & $3.03 \pm 0.01^{(a)}$ & $4.88 \pm 0.01^{(b)}$ & $5.41 \pm 0.21^{(\mathrm{c})}$ & $5.48 \pm 0.03^{(\mathrm{d})}$ \\
\hline & EPS-packed & & $3.03 \pm 0.01^{(a)}$ & $4.01 \pm 0.31^{(b)}$ & $4.43 \pm 0.21^{(b)}$ \\
\hline \multirow[t]{2}{*}{ Metmyoglobin (\%) } & PVC-packed & $19.67 \pm 1.27^{(\mathrm{a})}$ & $24.70 \pm 0.34^{(\mathrm{b})}$ & $49.24 \pm 1.41^{(\mathrm{c})}$ & $51.09 \pm 1.50^{(\mathrm{c})}$ \\
\hline & EPS-packed & & $21.70 \pm 1.40^{(\mathrm{a})}$ & $26.12 \pm 3.91^{(\mathrm{d})}$ & $31.98 \pm 4.48^{(\mathrm{d})}$ \\
\hline \multirow[t]{2}{*}{ Heme iron $\mathrm{Fe}^{3+}\left(\mu \mathrm{g} \cdot \mathrm{g}^{-1}\right)$} & PVC-packed & $5.08 \pm 0.39^{(a)}$ & $4.05 \pm 0.02^{(b)}$ & $3.52 \pm 0.34^{(\mathrm{c})}$ & $3.09 \pm 0.22^{(\mathrm{c})}$ \\
\hline & EPS-packed & & $5.07 \pm 0.40^{(\mathrm{a})}$ & $5.01 \pm 0.11^{(\mathrm{a})}$ & $4.87 \pm 0.11^{(\mathrm{a})}$ \\
\hline \multirow[t]{2}{*}{ Malondialdehyde (mg. $\mathrm{kg}^{-1}$ ) } & PVC-packed & $0.12 \pm 0.06^{(a)}$ & $0.36 \pm 0.03^{(\mathrm{a})}$ & $0.61 \pm 0.01^{(\mathrm{b})}$ & $0.82 \pm 0.06^{(\mathrm{d})}$ \\
\hline & EPS-packed & & $0.15 \pm 0.02^{(a)}$ & $0.22 \pm 0.02^{(\mathrm{c})}$ & $0.25 \pm 0.04^{(\mathrm{e})}$ \\
\hline \multirow[t]{2}{*}{ Total volatile basic nitrogen $\left(\mathrm{mg} \cdot \mathrm{Kg}^{-1}\right)$} & PVC-packed & $5.22 \pm 1.13^{(\mathrm{a})}$ & $14.38 \pm 2.93^{(\mathrm{b})}$ & $29.89 \pm 1.69^{(\mathrm{c})}$ & $32.31 \pm 1.50^{(\mathrm{e})}$ \\
\hline & EPS-packed & & $11.23 \pm 2.34^{(\mathrm{b})}$ & $19.22 \pm 3.41^{(\mathrm{d})}$ & $22.96 \pm 2.21^{(\mathrm{f})}$ \\
\hline
\end{tabular}

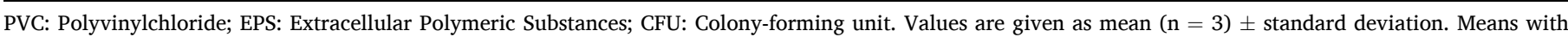
different superscripts $(\mathrm{a}-\mathrm{f})$ within a same row indicate significant difference $(p<0.05)$.

drip loss in the packed EPS meat samples did not exceed $9.0 \pm 0.6 \%$ after 9 days of storage while it reached $18.0 \pm 2.0 \%$ at day 3 and $23.0 \pm 4.0 \%$ at day 9 in the case of PVC-packed meat (Table 2). Higher drip losses are usually linked to an undesirable soft texture and deteriorate the meat palatability including its tenderness and juiciness [66]. It is believed that the drip loss was mainly caused by the oxidation of proteins which may result in damage to the meat structure [67].

Denaturation of proteins also induces the transfer of water from myofibrils to the extracellular space and thus increases the available water [68]. During the whole experimental storage period, the water activity (aw) was not significantly $(p<0.05)$ affected $(0.89 \pm 0.00)$ in meat packed with EPS film (Table 2). However, PVC-packed meat showed a significant aw increase (from $0.89 \pm 0.01$ to $0.95 \pm 0.01$ ) after 9 days of postmortem cold storage. In a general way, water availability represents a favorable environment where the microflora can develop. A higher value of aw indicates higher microbial spoilage of food products [69]. In the present work, the quantitative microflora status of the PVCpacked meat samples exceeded the regulatory UE standards for human consumption after 3 days of storage [70]. The total viable counts TVC increased from $3.03 \pm 0.01$ to $5.48 \pm 0.03$ CFU.g ${ }^{-1}$ and Pseudomonas loads increased from $2.03 \pm 0.01$ to $6.9 \pm 0.03$ CFU. ${ }^{-1}$ in PVC-packed meat samples (Table 2). In EPS film packed samples, both TVC value $\left(3.03 \pm 0.01\right.$ to $\left.4.04 \pm 0.21 \mathrm{CFU}^{-1}\right)$ and Pseudomonas sp. counts $\left(2.03 \pm 0.01\right.$ to $\left.4.09 \pm 0.21 \mathrm{CFU} . \mathrm{g}^{-1}\right)$ remained within the regulatory standards even after 9 days of cold storage [70].

The meat packed with Graesiella sp., EPS film showed a total volatile basic nitrogen (TVB-N) value of $22.96 \pm 2.50 \mathrm{mg} \cdot \mathrm{kg}^{-1}$ at the end of the storage period, while the PVC-packed meat had a TVB-N value of $32.31 \pm 1.50 \mathrm{mg} \cdot \mathrm{kg}^{-1}$ which is higher than the standard limits $(\leq 30 \mathrm{mg}$ of TVB-N $\cdot \mathrm{kg}^{-1}$ ) [71]. TVB-N is commonly used as an indicator of meat spoilage. High TVBN values are correlated with the presence of breakdown bacteria, decomposing the meat protein [72].

Metmyoglobin (Mmb) is resulting from the oxidation of myoglobin (the bright red pigment) [73]. An increase in Mmb level is a consequence of the not acceptable brown meat color and represents the early stages in the development of meat oxidative rancidity [74]. During storage, the rate of Mmb in the PVC-packed meat samples reached $49.24 \pm 1.27 \%$ on day 3 and $51.09 \pm 1.50 \%$ on day 9 (Table 2), leading to consequent meat discoloration. At the same storage period, the level of Mmb in the EPS packed meat samples increased only by $20.70 \pm 1.40 \%$ on day 3 and only $31.98 \pm 4.48 \%$ at the end of the experiment (day 9).

Heme iron represents the ferrous $\left(\mathrm{Fe}^{2+}\right)$ bound with the heme molecules, as hemoglobin or myoglobin. In this work, a significant decrease of heme iron concentration was observed in PVC-packed meat samples reaching $36 \%$ of the initial concentration since the third day and $61 \%$ at the end of storage (Table 2). This fact decreases the nutritive value of meat due to the oxidation of polyunsaturated fatty acids, which produce an undesirable flavor and aroma $[9,75]$. Hence, EPS film as a meat packaging material presents a great efficiency in preventing heme iron oxidation mainly linked to its potent metal chelating power. In the packed EPS film meat samples, the heme iron loss occurred only on day 9 of the storage and was evaluated to be only $4 \%$.

The degree of oxidation of the lipids contained in the meat samples was evaluated by measuring the malondialdehyde (MDA) content. MDA is commonly considered a marker of cell polyunsaturated fatty acids peroxidation. MDA is also considered a highly toxic molecule [75]. For both EPS-packed and PVC-packed meat samples and during the whole cold storage period, the level of MDA content did not exceed $1.0 \mathrm{mg}$ MDA $\cdot \mathrm{kg}^{-1}$ (Table 2) being the value considered as intolerable levels of rancidity taste in meat [63]. In meat samples packed with EPS film, the level of MDA reached a maximum value of $0.25 \pm 0.04 \mathrm{mg} \mathrm{MDA} \cdot \mathrm{kg}^{-1}$ at day 9. However, in PVC-packed meat samples, the MDA content was five times higher, reaching $0.82 \pm 0.06 \mathrm{mg} \mathrm{MDA} \cdot \mathrm{kg}^{-1}$ at day 9. This value exceeds $0.5 \mathrm{mg} \mathrm{MDA} \cdot \mathrm{kg}^{-1}$ which indicates lipid oxidation [63].

Non-substantial variation in the color of EPS packed meat was noticed during the whole storage period (Table 3). In contrast for PVCpacked meat samples, a significant reduction of the redness (from

Table 3

Evolution of meat color during the storage period at $4{ }^{\circ} \mathrm{C}$.

\begin{tabular}{llll}
\hline & $\mathrm{L}^{*}$ & $\mathrm{a}^{*}$ & $\mathrm{~b}^{*}$ \\
\hline Initial & $30.77 \pm 1.22^{(\mathrm{a})}$ & $13.61 \pm 0.55^{(\mathrm{a})}$ & $11.21 \pm 0.82^{(\mathrm{a})}$ \\
& & & \\
Day 3 & $39.72 \pm 0.19^{(\mathrm{b})}$ & $12.43 \pm 0.17^{(\mathrm{b})}$ & $14.68 \pm 0.48^{(\mathrm{b})}$ \\
PVC-packed & $28.77 \pm 2.23^{(\mathrm{a})}$ & $13.61 \pm 0.57^{(\mathrm{a})}$ & $10.02 \pm 0.87^{(\mathrm{a})}$ \\
EPS-packed & & \\
Day 6 & $39.2 \pm 0.17^{(\mathrm{c})}$ & $10.34 \pm 0.61^{(\mathrm{c})}$ & $18.48 \pm 1.31^{(\mathrm{c})}$ \\
PVC-packed & $33.77 \pm 1.23^{(\mathrm{a})}$ & $13.60 \pm 0.57^{(\mathrm{a})}$ & $12.18 \pm 0.27^{(\mathrm{a})}$ \\
EPS-packed & & & \\
Day 9 & $45.01 \pm 1.92^{(\mathrm{d})}$ & $7.93 \pm 0.13^{(\mathrm{d})}$ & $22.80 \pm 0.26^{(\mathrm{d})}$ \\
PVC-packed & $35.77 \pm 0.23^{(\mathrm{a})}$ & $13.60 \pm 0.47^{(\mathrm{a})}$ & $13.02 \pm 0.97^{(\mathrm{a})}$ \\
EPS-packed & & & \\
\hline
\end{tabular}

L*: lightness; a*: redness; b*: yellowness; PVC: Polyvinylchloride; EPS: Extracellular Polymeric Substance; Values are expressed as mean $(n=4) \pm$ standard deviation. Different letters indicate significant differences $(p<0.05)$. 
$13.61 \pm 0.55$ up to $7.93 \pm 0.13$ ) and a substantial increase of lightness (from $30.77 \pm 1.22$ to $45.01 \pm 1.92)$ and yellowness $(11.21 \pm 0.82$ to $22.80 \pm 0.26$ ) were observed since the third day of the storage period. According to Del Rio et al. [75] the change in meat color is correlated to the presence of metmyoglobin. Saucier et al. [76] explain that color changes with progressing processes of meat spoilage and especially emphasize the oxidative processes. Thus, EPS film was a significant improvement considering the shelf life of meat up to nine days, while meat packed with PVC-film exhibited a shelf life limited to three days.

\section{Conclusion}

This study investigates physicochemical, mechanical, optical, and antioxidant properties of the thermophilic microalgae Graesiella sp., EPS film. The structure analyses revealed the compact and homogenous structure of the EPS film. Despite its low elasticity and elongation at break, compared to other synthetic films, EPS film exhibited a high puncture resistance, low permeability to water vapor, low values of water content and swelling degree, high oxygen barrier properties, high thermal stability and high transparency and was highly UV light absorber. Furthermore, EPS film exhibited a strong antioxidant potential by inhibiting free radicals chain reactions and by chelating iron involved in lipid oxidation.

Applying EPS film in meat packaging extended the shelf life of meat during cold storage by limiting microbiological spoilage and reducing traits quality losses regarding lipid oxidation, protein degradation and discoloration.

Thus, Graesiella sp. EPS films show high potential as a multi-active packaging material for cold preservation of meat and, presumably, for various other food products, whether fresh or processed, such as cuts or comminuted materials from sheep, pigs, or fish. They offer an alternative to replace polluting synthetic packaging with a natural, biodegradable, and food-grade material. However, separate validation for each product may be required prior to use/recommend the films for packaging since their physicochemical properties differ from those of beef.

In another hand, EPS are poorly valued in industrial cultures of microalgae despite their high productivity, especially in thermophilic species. EPS are generally discarded with the culture medium after recovery of the biomass. Recycling them as active packaging material would, on the one hand, make the algae industry more profitable and, on the other hand, better protect the environment against organic waste.

Nevertheless, more research is needed to optimize the EPS recovery processes, to ensure the absence of possible toxicity, and to assess the economic feasibility prior to its massive use as food packaging material.

\section{Authors' agreement to authorship and submission}

All the authors agreed to the authorship and submission of the manuscript to Algal Research for peer review.

\section{Statement of informed consent, human/animal rights}

No conflicts, informed consent, or human or animal rights are applicable to this study.

\section{CRediT authorship contribution statement}

WG: conceived the original idea, carried out the experiment, and wrote the manuscript with input from all authors; Both JLGP and NC: authors interpreted the results contributed to the final version of the manuscript; SS: aided in interpreting the results and worked on the manuscript; HBO: contributed to the analysis of the results and to the writing of the manuscript and supervised the project.

All authors provided critical feedback and helped shape the research, analysis and manuscript.
We have no conflicts of interest to disclose.

\section{Declaration of competing interest}

The authors declare that they have no known competing financial interests or personal relationships that could have appeared to influence the work reported in this paper.

\section{Acknowledgments}

This research was supported by the National Institute of Marine Sciences and Technology of Tunisia (Laboratory of B3 Aqua) and the Tunisian Testing Service TTS (Monastir Technology Center-Tunisia). The authors would like to thank Mr. Jalel Abderrahman, Technical Manager, and all team at TTS Company for their help and enthusiasm.

\section{References}

[1] R.C. Thompson, C.J. Moore, F.S. vomSaal, S.H. Swan, Plastics, the environment and human health: current consensus and future trends, Philos. Trans. R. Soc. Lond. Ser. B Biol. Sci. 364 (2009) 2153-2166.

[2] EUROSTAT, Packaging waste statistics - Statistics Explained. https://ec.europa.eu/ eurostat/statisticsexplained/index.php/Packaging_waste_statistics, 2018. (Accessed 17 June 2020).

[3] Energy and Oceans Ministerscollab < collab $>$ OECD for the G7 Environment, Improving Plastics Management: Trends, policy responses, and the role of international co-operation and trade. https://www.oecd.org/environment/waste/ policy-highlights-improving-plastics-management.pdf, 2008.

[4] C. Contini, M.G. Katsikogianni, F.T. O’Neill, M. O'Sullivan, D.P. Denis, J. Frank, Development of active packaging containing natural antioxidants, in: Procedia Food Science, 11th International Congress on Engineering and Food (ICEF11) 1, 2011, pp. 224-228.

[5] Y. Yang, F. Feng, Q. Zhou, F. Zhao, R. Du, Z. Zhou, Y. Han, Isolation, purification, and characterization of exopolysaccharide produced by Leuconostoc Citreum N21 from dried milk cake, Trans. Tianjin Univ. 25 (2019) 161-168, https://doi.org/ 10.1007/s12209-018-0143-9.

[6] D. Granatoa, N.D. Nunes, J.F. Barba, An integrated strategy between food chemistry, biology, nutrition, pharmacology, and statistics in the development of functional foods: a proposal, Trends Food Sci. Technol. 62 (2016) 13-22.

[7] S. Quintavalla, L. Vicini, Antimicrobial food packaging in meat industry, Meat Sci. 37 (2002) 3-380.

[8] D. Plackett, Biopolymers: New Materials for Sustainable Films and Coatings, John Wiley \& Sons, 2011.

[9] V. Coma, Bioactive packaging technologies for extended shelf life of meat-based products, Meat Sci. 78 (2008) 90-103.

[10] J.H. Han, A review of food packaging technologies and innovations, in: J.H. Han (Ed.), Food Science and Technology. Academic Press, San Diego, 2014 (Chapter 1).

[11] T. Senturk Parreidt, K. Müller, M. Schmid, Alginate-based edible films and coatings for food packaging applications, Foods 7 (2018) 170.

[12] N. Mezhoud, F. Zili, N. Bouzidi, F. Helaoui, J. Ammar, H.B. Ouada, The effects of temperature and light intensity on growth, reproduction and EPS synthesis of a thermophilic strain related to the genus Graesiella, Bioprocess Biosyst. Eng. 37 (2014) 2271-2280.

[13] W. Gongi, N. Cordeiro, J.L.G. Pinchetti, H. Ben ouada, Production of exopolymer substances from the thermophilic chlorophyte graesiella: industrial and ecological applications, J. Appl. Phycol. 33 (2021) 357-369. https://doi.org/10.1007 /s10811-020-02303-0.

[14] R. Xiao, Y. Zheng, Overview of microalgal extracellular polymeric substances (EPS) and their applications, Biotechnol. Adv. 34 (2016) 1225-1244.

[15] N. Gontard, S. Guilbert, J.L. Cuq, Edible wheat gluten films: influence of main process variables on film properties using response surface methodology, J. Food Sci. 57 (1992) 190-195.

[16] American Society for Testing and Materials (ASTM), Standard test methods for tensile properties of thin plastic sheeting (standard designation: D882), in: Annual Book of American Standards Testing Methods, Philadelphia, PA, 1985, pp. $182-188$.

[17] C. Pastor, L. Sánchez-González, M. Cháfer, A. Chiralt, C. González-Martínez, Physical and antifungal properties of hydroxypropylmethylcellulose based films containing propolis as affected by moisture content, Carbohydr. Polym. 82 (2010) 1174-1183.

[18] Y. Peng, Y. Li, Combined effects of two kinds of essential oils on physical, mechanical and structural properties of chitosan films, Food Hydrocoll. 36 (2014) 287-293, https://doi.org/10.1016/j.foodhyd.2013.10.013.

[19] American Society for Testing and Materials (ASTM), Standard test method for oxygen gas transmission rate through plastic film and sheeting using a coulometric sensor (D3985-05), in: Annual Book of ASTM Standards, Philadelphia, PA, 2005.

[20] American Society for Testing and Materials (ASTM), Standard test method for water vapor transmission of materials Designation (E96-E 80), in: Annual Book of ASTM Standards, Philadelphia, PA, 1989, pp. 730-739.

[21] P. Prieto, M. Pineda, M. Aguilar, Spectrophotometric quantitation of antioxidant capacity through the formation of a phosphomolybdenum complex: specific 
application to the determination of vitamin E, Anal. Biochem. 269 (1999) 337-341.

[22] A. Dapkevicius, R. Venskutonis, T.A. Beek, J.P.H. Linssen, Antioxidant activity of extracts obtained by different isolation procedures from some aromatic herbs grown in Lithuania, J. Sci. Food Agric. 77 (1998) 140-146.

[23] K. Shimada, K. Fujikawa, K. Yahara, T. Nakamura, Antioxidative properties of xanthan on the autoxidation of soybean oil in cyclodextrin emulsion, J. Agric. Food Chem. 6 (2002) 945-948.

[24] M. Oyaizu, Studies on products of browning reaction. Antioxidative activities of products of browning reaction prepared from glucosamine, Jpn. J. Nutr. Dietetics 44 (1986) 307-315.

[25] M. Wettasinghe, F. Shahidi, Iron (II) chelation activity of extracts of borage and evening primrose meals, Food Res. Int. 35 (2002) 65-71.

[26] C.D. Allen, D.L. Fletcher, J.K. Northcutt, S.M. Russell, The relationship of broiler breast color to meat quality and shelf-life, Poult. Sci. 77 (1998) 361-366.

[27] K. Krzywicki, Assessment of relative content of myoglobin, oxymyoglobin and metmyoglobin at the surface of beef, Meat Sci. 3 (1979) 1-10.

[28] E.M. Clark, A.W. Mahoney, C.E. Carpenter, Heme and total iron in ready-to-eat chicken, J. Agric. Food Chem. 45 (1997) 124-126.

[29] A.J. Buege, S.D. Aust, Microsomal lipid peroxidation, Methods Enzymol. 52 (1972) 302-310.

[30] S. Datta, A. Akter, I. Shah, K. Fatema, T. Islam, A. Bandyopadhyay, Z. Khan, D. Biswas, Microbiological quality assessment of raw meat and meat products, and antibiotic susceptibility of isolated Staphylococcus aureus, Agric. Food Anal. Bacteriol. 2 (2012) 187-194.

[31] O. Skurtys, C.A. Acevedo, F. Pedreschi, J. Enrione, F. Osorio, J.M.C. Aguilera, in: Food Hydrocolloid Edible Films and Coatings 66, Nova Science Publishers, 2010, pp. 1-34.

[32] Z. Hanani, E. Beatty, Y.H. Roos, M.A. Morris, J.P. Kerry, Development and characterization of biodegradable composite films based on gelatin derived from beef, pork and fish sources, Foods 2 (2013) 1-17, https://doi.org/10.3390/ foods 2010001.

[33] M. Jridi, S. Hajji, H. Ben, I. Ayed, A. Lassoued, M. Mbarek, N. Kammoun, M. Nasri Souissi, Physical, structural, antioxidant and antimicrobial properties of gelatin-chitosan composite edible films, Int. J. Biol. Macromol. 67 (2014) 373-379, https://doi.org/10.1016/j.ijbiomac.2014.03.054.

[34] D. Santhiya, S. Subramanian, K.A. Natarajan, Surface chemical studies on sphalerite and galena using extracellular polysaccharides isolated from Bacillus polymyxa, J. Colloid Interface Sci. 256 (2002) 237-248.

[36] D. Radhika, A. Mohaideen, Fourier transform infrared analysis of Ulva lactuca and Gracilaria corticata and their effect on antibacterial activity, Asian J. Pharm. Clin. Res. 8 (2015) 209-212 [Google Scholar].

[35] M.Da Rocha, C. Prentice, Biodegradable films: an alternative food packaging, Chapter 9, in: A.M. Grumezescu, A.M. Holban (Eds.), Handbook of Food Bioengineering, Food Packaging and Preservation, 1st ed. 9, Academic Press, Cambridge, MA, USA, 2018, pp. 307-342 [CrossRef].

[37] P. Arabkhani, H. Javadian, A. Asfaram, M. Ateia, Decorating graphene oxide with zeolitic imidazolate framework (ZIF-8) and pseudo-boehmite offers ultra-high adsorption capacity of diclofenac in hospital effluents, Chemosphere 610 (2021) 129, https://doi.org/10.1016/j.chemosphere.2021.129610. Epub 2021 Jan 11.

[38] A. Asfaram, E. Alipanahpour Dil, P. Arabkhani, F. Sadeghfar, M. Ghaedi, Magnetic $\mathrm{Cu}$ : CuO-GO nanocomposite for efficient dispersive micro-solid phase extraction of polycyclic aromatic hydrocarbons from vegetable, fruit, and environmental water samples by liquid chromatographic determination, Talanta 218 (2020) 121-131, https://doi.org/10.1016/j.talanta.2020.121131.

[39] A. Taqi, K.A. Askar, K. Nagy, L. Mutihac, I. Stomatin, Effect of different concentrations of olive oil and oleic acid on the mechanical properties of albumen (egg white) edible films, Afr. J. Biotechnol. 10 (2011) 12963-12972.

[40] A. Simeonov, K. Michaelian, Properties of cyanobacterial UV-absorbing pigments suggest their evolution was driven by optimizing photon dissipation rather than photoprotection, Biol. Phys. 58 (2019) 1-37.

[41] L. Wang, L. Liu, J. Holmes, J.F. Kerry, J.P. Kerry, Assessment of film-forming potential and properties of protein and polysaccharide-based biopolymer films, Int. J. Food Sci. Technol. 42 (2007) 1128-1138.

[42] T. Finkel, N.J. Holbrook, Oxidants, oxidative stress and the biology of ageing, Nature 408 (2000) 239-247.

[43] J.K.S. Moller, G. Bertelsen, L.H. Skibsted, Photooxidation of nitrosomyoglobin at low oxygen pressure. Quantum yields and reaction stoechometries, Meat Sci. 60 (2002) 421-425.

[44] B.L. Butler, P.J. Vergano, R.F. Testin, J.M. Bunn, J.L. Wiles, Mechanical and barrier properties of edible chitosan films as affected by composition and storage, J. Food Sci. 61 (1996) 953-995.

[45] J.M. Krochta, in: A. Gennadios (Ed.), Protein-based Films and Coatings, CRC Press, Boca Raton, 2002.

[46] N. Suderman, M.I.N. Isa, N.M. Sarbon, Characterization on the mechanical and physical properties of chicken skin gelatin films in comparison to mammalian gelatin films, IOP Conf. Ser. Mater. Sci. Eng. 440 (2018) 012033.

[47] N.M. Sarbon, F. Badii, N.K. Howell, Preparation and characterization of chicken skin gelatin as an alternative to mammalian gelatin, Food Hydrocoll. 30 (2013) $143-151$.

[48] C. Valencia-Sullca, M. Vargas, L. Atarés, A. Chiralt, Thermoplastic cassava starchchitosan bilayer films containing essential oils, Food Hydrocoll. 75 (2018) $107-115$.
[49] K. Mazeau, M. Rinaudo, The prediction of the characteristics of some polysaccharides from molecular modeling.Comparison with effective behavior 18 (2004) 885-898.

[50] V. Siracusa, Food packaging permeability behaviour: a report, Int. J. Polym. Sci. 11 (2012) 302-329, https://doi.org/10.1155/2012/302029.

[51] L. Wang, M.A.E. Auty, J.P. Kerry, Physical assessment of composite biodegradable films manufactured using whey protein isolate, gelatin and sodium alginate, J. Food Eng. 96 (2010) 199-207, https://doi.org/10.1016/j. jfoodeng.2009.07.025.

[52] J.M. Krochta, C., De mulder-Johnston, edible and biodegradable polymer films: challenges and opportunities, Food Technol. 2 (1997) 61-64.

[53] N. Gontard, S. Guilbert, J.L. Cuq, Water and glycerol as plasticizers affect mechanical and water vapor barrier properties of an edible wheat gluten film, J. Food Sci. 58 (1993) 206-211.

[54] P. Rachtanapun, W. Klunklin, P. Jantrawut, K. Jantanasakulwong, Y. Phimolsiripol, P. Seesuriyachan, N. Leksawasdi, T. Chaiyaso, W. Ruksiriwanich, S. Phongthai, S.R. Sommano, W. Punyodom, A. Reungsang, T.M.P. Ngo, Characterization of chitosan film incorporated with curcumin extract, Polymers 13 (2021) 963, https://doi.org/10.3390/polym13060963.

[55] L. Minbo, Antioxidant and anti-tumor activities of purified polysaccharides with low molecular weights from Magnolia officinalis 6 (2012) 1025-1034, https://doi. org/10.5897/jmpr11.780.

[56] J.Y. Yin, S.P. Nie, C. Zhou, Y. Wan, M.Y. Xie, Chemical characteristics and antioxidant activities of polysaccharide purified from the seeds of Plantago asiatica L, J. Sci. Food Agric. 90 (2010) 210-217, https://doi.org/10.1002/jsfa.3793.

[57] M. Andrew, G. Jayaraman, Structural features of microbial exopolysaccharides in relation to their antioxidant activity, Carbohydr. Res. 487 (2020) 107-881, https://doi.org/10.1016/j.carres.2019.107881.

[58] R.A. Mancini, M.C. Hunt, Current research in meat colour, Meat Sci. 71 (2005) $100-121$.

[59] E. Barbara, G. Lynn, Oxidation-induced colour and flavor changes in meat, J. Agric. Food Chem. 23 (1975) 164-167.

[60] K. Raj, U.R. Sardar, E. Bhargavi, I. Devi, B. Bhunia, O.N. Tiwari, Advances in exopolysaccharides-based bioremediation of heavy metals in soil and water: a critical review, Carbohydr. Polym. 199 (2018) 353-364, https://doi.org/10.1016/ j.carbpol.2018.07.037.

[61] L. Parwani, M. Bhatnagar, A. Bhatnagar, V. Sharma, Antioxidant and iron-chelating activities of cyanobacterial exopolymers with potential for wound healing, J. Appl. Phycol. 26 (2014) 1473-1482, https://doi.org/10.1007/s10811-013-0180-7.

[62] R. Dutson, The measurement of $\mathrm{pH}$ in muscle and its importance to meat quality Thayne, in: Report on Annual Plan of Work Accomplishments, 2003.

[63] P. Warriss, Meat Science: An Introductory Text, 2nd edition, University of Bristol, UK, 2000.

[64] P. Masniyom, S. Benjakul, W. Visessanguan, Shelf-life extension of refrigerated seabass slices under modified atmosphere packaging, J. Sci. Food Agric. 82 (2002) $873-880$.

[65] S. Stajkovic, D. Vasilev, V. Teodorovic, N. Karabasil, Postmortem glycolysis and pork quality, IOP Conf. Ser. Earth Environ. Sci. 333 (2019) 12-32.

[66] E. Huff-Lonergan, Fresh meat water-holding capacity, in: J.P. Kerry, D. Ledward (Eds.), Improving the Sensory and Nutritional Quality of Fresh Meat, Technology and Nutrition. Woodhead Publishing, Woodhead Publishing Series in Food Science, 2009, pp. 147-160.

[67] S. Traore, L. Aubry, P. Gatellier, W. Przybylski, D. Jaworska, K. Kajak-Siemaszko, V. Santé-Lhoutellier, Higher drip loss is associated with protein oxidation, Meat Sci. 90 (2012) 917-924.

[68] A. Sundrum, Quality in organic, low-input and conventional pig production, in: J. Cooper, U. Niggli, C. Leifert (Eds.), Handbook of Organic Food Safety and Quality, Woodhead Publishing Series in Food Science, Technology and Nutrition. Woodhead Publishing, 2007, pp. 144-177.

[69] E. Sandulachi, Water activity concept and its role in food preservation, Meridian Eng. 4 (2012) 40-48.

[70] EFSA, Scientific Opinion on Campylobacter in broiler meat production: control options and performance objectives and/or targets at different stages of the food chain, EFSA Journal 9 (2011) 2105.

[71] M. Zhang, X. Meng, B.N. Bhandari, Z. Fang, H. Chen, Recent application of modified atmosphere packaging (MAP) in fresh and fresh-cut foods, Food Rev. Int. 31 (2015) 172-193 [CrossRef].

[72] Y. Cao, W. Gu, J. Zhang, Y. Chu, X. Ye, Y. Hu, J. Chen, Effects of chitosan, aqueous extract of ginger, onion and garlic on quality and shelf life of stewed pork during refrigerated storage, Food Chem. 141 (2013), 1655-16.

[73] Cornforth, Colour its basis and importance, in: A.M. Pearson, T.R. Dutson (Eds.), Quality Attributes and Their Measurement in Meat, Poultry and Fish Products. Advances in Meat Research, Springer US, Boston, MA, 1994, pp. 34-78.

[74] J. Kanner, J.B. German, J.F. Kinsella, Initiation of lipid peroxidation in biological systems, CRC Crit. Rev. Food Sci. Nutr. 25 (1987) 64-317.

[75] D. Del Rio, A.J. Stewart, N. Pellegrini, A review of recent studies on malondialdehyde as toxic molecule and biological marker of oxidative stress, Nutr. Metab. Cardiovasc. Dis. 15 (2005) 316-328.

[76] L. Saucier, C. Gendron, C. Gariepy, Shelf life of ground poultry meat stored under modified atmosphere, Poult. Sci. 79 (2000) 1851-1856, https://doi.org/10.1093/ ps/79.12.1851. 